ISSN: 1641-4713; e-ISSN: 2081-1160

DOI: https://doi.org/10.36551/2081-1160.2020.25.25-56

\title{
Gestionando el buen vivir en un entorno local. Estrategia transdisciplinaria y colaboración en red en la periferia de Xalapa, México
}

\author{
Managing Good Living in a Local Environment: Transdisciplinary \\ Strategy and Networking in the Periphery of Xalapa, Mexico
}

Recepción: 8.12.2019

Aprobación: 6.04.2020

\author{
Krystyna Barbara Paradowska \\ Centro de Ecoalfabetización y Diálogo de Saberes \\ Universidad Veracruzana, México \\ ID ORCID: https://orcid.org/0000-0002-8341-1002 \\ E-mail: kparadowska@yahoo.com.mx, kparadowska@uv.mx
}

Resumen: El trabajo contribuye al diálogo intercultural sobre la construcción de otros mundos posibles a partir de la propuesta de buen vivir y su redefinición desde acciones locales en la ciudad Xalapa (Veracruz, México). Se retoma el carácter abierto del concepto acuñado por los pueblos originarios del área andina como alternativa al desarrollo, para plantearlo como horizonte apto para unir esfuerzos en la defensa y la cogestión de espacios de vida diversos con problemáticas propias, como pueden ser las ciudades y zonas rurales contiguas a grandes urbes. El articulo resalta el papel protagónico de la sociedad civil organizada y redes vecinales informales en la cogestión del buen vivir, reconociendo también el rol de la universidad en la construcción de estrategias dialógicas y transdisciplinarias hacia horizontes de vida más sustentables y justos. En este contexto, se comparten las experiencias y aprendizajes del proyecto Diálogo de saberes para el buen vivir, impulsado como estrategia de resistencia local en la periferia rural de la ciudad amenazada por los efectos del crecimiento de la mancha urbana. La autora explora el proceso de desbordamiento de las acciones colaborativas hacia tiempos y espacios cotidianos y la necesaria implicación del facilitador en los procesos de transformación que promueve.

Palabras clave: buen vivir, epistemologías del sur, diálogo de saberes, metodología transdisciplinaria, redes colaborativas. 


\begin{abstract}
This paper contributes to the intercultural dialogue about the possibilities of constructing alternative worlds, starting from the notion of "good living" (buen vivir) and its resignification through local actions in the city of Xalapa (Veracruz, Mexico). The open character of the concept, coined by the native peoples of the Andean area as an alternative to development, is retaken here as a pertinent horizon in the field of defense and co-management of diverse spaces of life, such as rural areas adjacent to big cities. The work highlights the leading role of organized civil society and informal neighborhood networks in co-managing the good living on a local scale and recognizes the role of the university in the construction of dialogic and transdisciplinary strategies towards a more sustainable and fair life. In this context, we share experiences and learnings of the project named "Knowledge for Dialogue for Good Living", considered as a strategy for local resistance threatened by the effects of urban spot growth in the rural periphery of the city. The author explores the process of "overflowing" of collaborative actions in everyday times and spaces and the necessary involvement of the facilitator in the transformation processes that she promotes.
\end{abstract}

Keywords: good living, epistemologies of the South, dialogue of knowledge, transdisciplinary methodology, collaborative networks.

"Sin utopía la vida sería un ensayo para la muerte." Joan Manuel Serrat, Utopía

\title{
INTRODUCCIÓN
}

Este trabajo se sitúa en el contexto de la efervescencia de las iniciativas no-hegemónicas en la región de Xalapa, Veracruz, México empeñadas abiertamente en contrarrestar los efectos del desarrollo que ha impactado negativamente en el medioambiente y en el tejido social en la ciudad y sus alrededores. Esta actividad, alimentada por los importantes antecedentes de lucha de los movimientos ambientalistas y la vigencia de prácticas tradicionales en la región, se intensifica en el contexto de la creación del Área Natural Protegida Archipiélago de Bosques y Selvas de Xalapa en 2015, que abrió un marco para la colaboración de diversos actores y colectivos, coincidentes en la búsqueda y experimentación de lógicas y prácticas para el florecimiento armonioso de los valores ambientales, sociales y espirituales en la zona de influencia de esta nueva área natural protegida.

El tipo de desarrollo que aquí se cuestiona está directamente asociado al crecimiento caótico y voraz de la mancha urbana. En la región, los cambios de uso de suelo no sólo modifican el paisaje afectando la biodiversidad local, sino que también impactan en patrones de producción y consumo, despojan de bienes y privatizan espacios comunes, provocan el olvido, erosionan saberes y desaparecen oficios tradicionales, agrietando el tejido social y la convivialidad y debilitando el arraigo territorial de la gente. La lógica del desarrollo en las inmediaciones de la ciudad permea todas las esferas de vida social institucionalizada, pero 
también está colonizando las prácticas informales, íntimas y cotidianas en cuanto a las formas de relacionarnos con otros seres humanos y con la naturaleza, socavando las bases profundas donde yacen las capacidades de nuestra reinvención como sociedad.

$\mathrm{El}$ argumento del que parte este trabajo es que en este panorama de problemáticas inherentes al desarrollo y la emergencia de varios movimientos contestatarios, la noción de buen vivir puede ser retomada como una posible plataforma de diálogo y colaboración que oriente y dé sentido a las diversas expresiones de resistencia y recreación de prácticas sociales de carácter sustentable, de justicia epistémica, social y ambiental. Subrayemos que el buen vivir no es aquí entendido de manera ortodoxa como un credo único y acabado, sino colocado como un horizonte común que se persigue desde la diversidad de contextos, campos de acción y creatividad social a través de múltiples prácticas, situadas y dialogantes entre sí.

En nuestro contexto local, la noción de buen vivir se introduce de manera explícita a partir del proyecto Diálogo de saberes para el buen vivir, planteado como una iniciativa de vinculación entre la academia y la sociedad, que retoma esta noción ancestral de los pueblos originarios para redefinirla desde los entornos particulares. En su estrategia enfocada a propiciar espacios de reflexión y revitalización de elementos culturales afines al buen vivir, el proyecto se vinculó con otras iniciativas que comparten no sólo el mismo territorio de acción sino también las intenciones y formas de trabajar. Este encuentro se ha dado a partir del mutuo reconocimiento, del diálogo horizontal y, sobre todo, en el hacer compartido que nos retroalimenta en lo teórico al mismo tiempo que fortalece el impacto de las acciones realizadas desde esta coyuntura.

La intención de este trabajo es socializar el contexto y las experiencias del proyecto Diálogo de saberes para el buen vivir, articulado a otras iniciativas de carácter local y bio-regional, con el objetivo de visibilizar las vetas de buen vivir en este nicho multi-actoral y multicultural, y dar cuenta de la emergencia de colaboraciones que se tejen a partir de estas convergencias profundas, ayudando a transformar las lógicas y prácticas locales en torno a la educación, la comunicación, la producción y el consumo que, en su conjunto, desafían el modelo actual de desarrollo, cuidando nuestro entorno socio-ambiental más próximo. El texto intenta profundizar algunos aspectos, en particular respondiendo a tres preguntas: ¿Cómo se gestiona el buen vivir en un entorno local? ¿En qué consisten los principales logros y para qué nos sirven los aprendizajes generados en el hacer compartido? ¿Qué referencias teóricas y conceptuales pueden acotar mejor esta expe- 
riencia nacida de la inconformidad con el modelo actual del desarrollo aplicado a nuestros mundos de vida más cercanos, colectivos e íntimos?

A continuación, comparto las experiencias de cinco años de trabajo en el marco del mencionado proyecto que fue impulsado inicialmente como una iniciativa académica desde el Centro de Ecoalfabetización y Diálogo de Saberes Ecodiálogo- de la Universidad Veracruzana y que pronto se transformó en una búsqueda de estrategias de resistencia local al crecimiento de la mancha urbana, donde la noción de buen vivir se retomó para provocar un pensar y un hacer situado, colectivo y solidario. Comenzaré por describir brevemente el principal referente de este proyecto -la noción de buen vivir-, seguido por la ubicación de la iniciativa en el contexto del crecimiento de la ciudad caracterizado por su expansión hacia las áreas verdes y rurales, para continuar con la presentación de un abanico de acciones locales de autogestión afines al buen vivir que promueven alternativas de vida en la ciudad y sus márgenes. Resalto el aporte de la universidad y de la sociedad civil organizada a la gestión de espacios de reaprendizaje para una vida sustentable y acorde con el buen vivir en la región de Xalapa. Precedida por una aproximación al contexto rural de la localidad de Xoloxtla, pensada como un reducto de buen vivir que se resiste a cambiar bajo la presión de la urbanización y la globalización, se expone la estrategia y las principales experiencias de la indagación colaborativa desarrollada con los vecinos, las escuelas y la Red de Custodios del Área Natural Protegida Archipiélago de Bosques y Selvas de Xalapa. Finalmente, comparto algunas reflexiones que emergen como aprendizajes del proceso vivido, con el fin de nutrir nuevas búsquedas desde el enfoque trans-disciplinar y colaborativo.

\section{BUEN VIVIR COMO INVITACIÓN AL DIÁLOGO}

En América Latina, la crítica del desarrollo no es nueva ni parcial, y tampoco proviene de una fuente única sino que es la suma de voces y experiencias heterogéneas. Es vasta, contundente y omnipresente. El objeto de esta crítica son las prácticas excluyentes y los efectos destructivos que la aplicación del modelo ha producido en diversos aspectos de la vida, así como el tipo de racionalidad instrumental que los respalda (Escobar, 1996; 2016; Esteva et al., 2013; Illich, 2006-2008; Leff, 2004; Sachs, 1997). "La crisis ambiental es en el fondo una crisis de conocimiento", afirma Enrique Leff (2006: 27), refiriéndose a una "racionalidad cognitivo-instrumental de la modernidad" y de su modelo económico capitalista, que "desplaza su propósito de comprender la realidad hacia el objetivo 
de intervenir lo real (la naturaleza y la sociedad), y cuya más clara expresión es la tecnologización y la economización del mundo y de los mundos de vida de la gente" (2006: 59). Varios críticos de la modernidad han proporcionado argumentos contundentes sobre el carácter injusto, excluyente, equivocado e indolente del pensamiento occidental moderno, incluyendo la racionalidad científica (Nicolescu, 1996; Morin, 2004; Santos, 2009). "La indolencia de la razón"-concluye Boaventura de Sousa Santos- "se manifiesta, entre otras formas, en el modo como se resiste al cambio de las rutinas, y como transforma intereses hegemónicos en conocimientos verdaderos" (Santos, 2009: 9-10). En Latinoamérica el desarrollo se ha vivido como un discurso y una práctica que han perpetuado la desigualdad colonial con graves consecuencias sociales y ambientales. Al privatizar bienes públicos y al otorgar concesiones mineras, forestales, hidroeléctricas y agroindustrias a los intereses privados, el actual modelo neoliberal y extractivista ha debilitado el control estatal y comunitario sobre los territorios y ha afectado a los derechos fundamentales de las personas y de los pueblos enteros.

El paradigma positivista en que se ha sostenido la idea de desarrollo viene derrumbándose desde hace décadas. La construcción de un paradigma nuevo basado en formas más plurales, democráticas y respetuosas con la naturalezadepende de nuestra capacidad de apertura radical al diálogo intercultural y transdisciplinario. El reto requiere de un esfuerzo colectivo de autocrítica y creatividad, capaz de transformar nuestros pensamientos, relaciones y prácticas. La crisis de la modernidad sólo puede responderse situándonos frente a ella desde lógicas diferentes, a partir de una reconfiguración inesperada de actores, estrategias y alianzas, pues los actuales tomadores de decisión no han sido capaces de evitar los daños colaterales del desarrollo. "Nos enfrentamos a problemas modernos para los cuales no tenemos soluciones modernas", dice Boaventura de Sousa Santos, y por ello tendremos que encontrar otros marcos de referencia, abrirnos a los saberes "otros" coexistentes con el modelo neoliberal dominante, reconociendo que "la comprensión del mundo es mucho más amplia que la concepción occidental del mundo" (Santos, 2009: 150). La esperanza convoca a diversos sujetos e imaginarios, entre los cuales el "buen vivir" emerge como un discurso de resistencia, de reconstrucción de la sociedad y de nuestra relación con la naturaleza.

Las experiencias de América Latina, alimentadas por saberes populares y tradicionales de los pueblos indígenas, experiencias de lucha de los movimientos sociales y las teorías de la academia crítica, ofrecen una posibilidad de cambio. Sería prematuro afirmar que las transformaciones que estamos presenciando apuntan a una globalización alternativa, pero sabemos que se comparten en redes 
y se redefinen en entornos diversos. En el panorama de la región, la noción del buen vivir propuesta inicialmente por los movimientos de los pueblos originarios de los Andes, es uno de estos insumos que resuenan en otros discursos de resistencia y transformación social y se adaptan a otras prácticas de lucha (Huanacuni Mamani, 2010; Sartorello et al., 2012; Marañón, 2014; Paradowska, 2017).

El origen de la noción de buen vivir -la idea central de nuestro planteamiento - nos remite a los pronunciamientos de los pueblos andinos que a través de ella rescatan y reafirman los valores arraigados en la cosmovisión ancestral. En este proceso de cambio global que desafía al desarrollo, los líderes andinos afirman que "el buen vivir es nuestra propuesta al mundo":

El proceso de cambio que emerge hoy en la región, desde la visión de los pueblos ancestrales indígenas-originarios, irradia y repercute en el entorno mundial, promoviendo un paradigma, uno de los más antiguos: el "paradigma comunitario de la cultura de la vida para vivir bien", sustentado en una forma de vivir reflejada en una práctica cotidiana de respeto, armonía y equilibrio con todo lo que existe, comprendiendo que en la vida todo está interconectado, es interdependiente y está interrelacionado. (Huanacuni Mamani, 2010: 11)

Desde hace más de dos décadas existe una viva discusión sobre el aporte de la noción de buen vivir al cambio profundo en el panorama de los países, regiones o comunidades, especialmente rica en el mencionado ya contexto andino donde inclusive logró - para bien y para mal- una forma institucionalizada al integrarse en las constituciones de Ecuador y Bolivia. En este debate se destaca su papel en la reafirmación y revitalización cultural de los pueblos, su carácter contra-hegemónico, contra-capitalista y contra-desarrollista, y sus contribuciones a la reconfiguración de diferentes áreas de vida como la economía, la educación, el marco jurídico y, en especial, el reconocimiento del valor intrínseco de la naturaleza y de sus derechos. Caracterizando esta propuesta, Gudynas y Acosta apuntan a que éste "no es un desarrollo alternativo, sino alternativa a todas sus variantes"; corresponde a una visión de los marginados de la historia y es un escenario de resistencia al neocapitalismo y colonialismo; es una propuesta biocéntrica y socio-céntrica que retoma los saberes tradicionales y sus principios éticos en cuanto a las formas respetuosas de convivencia entre los seres humanos y con la Madre Tierra (Gudynas y Acosta, 2011; Francisco-Hidalgo, 2011).

Tanto los pueblos indígenas como algunos investigadores coinciden en que el buen vivir no es una propuesta total ni acabada: "No existe una receta para el buen vivir, y se lo debe construir en cada caso" (Gudynas, 2011: 244). El buen vivir se desprende de su contexto de origen, migra hacia otros entornos y se adapta como horizonte que resume múltiples iniciativas de lucha por un mundo mejor. Como señala Juliana Merçon, el buen vivir es la respuesta a múltiples 
inconformidades ante despojos y amenazas implícitas en el sistema hegemónico del mundo actual. La misma autora resume los principales rasgos de esta propuesta, señalando que: 1) tiene carácter contextual o situado, que significa que las acciones específicas hacia el buen vivir se construyen a partir de la cercanía como su principal referente; 2) es un concepto abierto, que se nutre y redefine a partir de las resistencias creativas y adaptativas; 3 ) es híbrido, porque abreva en diferentes tradiciones culturales y diferentes saberes, como los mencionados ya saberes tradicionales, populares y académicos; 4) es multi-actoral, porque su condición es que se construya en colectividad y para la colectividad; y 5) tiene carácter multi y trans-dimensional, lo cual significa que atraviesa e impacta diferentes dimensiones de la vida social y personal (Merçon, 2017).

Dado el carácter híbrido, contextual, polisémico y abierto de esta nociónhorizonte destacado por Merçon (2017), el buen vivir nos invita a pensarlo localmente y redefinirlo desde la particularidad. Sin duda, existe una infinidad de contextos socio-ambientales, con características propias, donde este se pueda defender o reconstruir. En territorios indígenas y zonas rurales amenazadas principalmente por el extractivismo o el narcotráfico es donde encuentra mayor resonancia, acompañando las luchas en defensa de bienes comunes, modos de organización comunitaria y autonomía. Pero también hay otros escenarios que enfrentan crisis, otras áreas de inconformidad y movilización en defensa de espacios y estilos de vida que ponderan la relación, el cuidado y la sustentabilidad sobre el individualismo, la acumulación y la explotación. Los entornos urbanos de la región, con su crecimiento caótico y voraz, es otro ambiente donde se generan problemáticas complejas en detrimento de la calidad de vida de sus habitantes e impactos irreversibles en el medioambiente.

Para finalizar esta parte quiero acotar que el buen vivir es aquí principalmente un pretexto y una invitación al diálogo sobre las posibilidades de construir alternativas al actual modelo de desarrollo y a la modernidad. El buen vivir en el contexto de nuestro proyecto se sitúa en el hacer y no en la definición. De algún modo, este trabajo aporta al reto de la traducción intercultural en el sentido que le confiere Boaventura de Sousa Santos cuando señala que "el trabajo de traducción es el procedimiento que nos queda para dar sentido al mundo después de haber perdido el sentido y la dirección automáticos que la modernidad occidental pretendió conferirle al planificar la historia, la sociedad y la naturaleza" (Santos, 2009). 


\section{LA EXPANSIÓN DE LA MANCHA URBANA Y LA VULNERABILIDAD DE LA PERIFERIA EN XALAPA}

El propósito del siguiente apartado es caracterizar el contexto urbano y periurbano de Xalapa, capital de estado del Veracruz e importante centro administrativo y educativo, trazando un panorama general del crecimiento y urbanización del área con el fin de señalar las consecuencias negativas de los procesos de desarrollo urbano de las últimas décadas en la vida de sus habitantes, los ecosistemas y agro-ecosistemas de su periferia rural.

El municipio de Xalapa, caracterizado por una topografía montañosa y accidentada con variedad de desniveles y un clima semicálido húmedo, se ubica en la cuenca media del río La Antigua, en un intervalo altitudinal que comprende desde los 600 msnm hasta los 1.600. De acuerdo a los estudios disponibles concentrados en el actual Plan Municipal de Desarrollo 2018-2021, el proceso de conformación territorial de la ciudad de Xalapa puede resumirse en cuatro momentos significativos a partir de su fundación en tiempos virreinales en lugar del anterior asentamiento prehispánico. El primero corresponde a una lenta construcción urbana, favorecida por su localización estratégica en la ruta comercial entre el puerto de Veracruz y la Ciudad de México en el altiplano, que se intensificó en el siglo XIX. A finales de siglo, en 170 hectáreas de la zona urbana vivían 22.000 habitantes. La ciudad colindaba con grandes haciendas - tales como la de Lucas Martín o el Molino de Pedreguera- dedicadas a la cría de ganado en la zona norte y al cultivo de café en la zona sur. La primera mitad del siglo XX corresponde a un crecimiento regulado acompañado por modificaciones en su entorno rural. Por una parte, en la periferia se instauraron los barrios obreros de familias de empleados en fábricas textiles; por otra, a raíz de la reforma agraria, que fraccionó y dotó de tierras a campesinos, las grandes extensiones de las haciendas se convierten en ejidos y en propiedades menores. En 1950, la ciudad ocupaba 593 hectáreas y albergaba a 59.000 residentes. La siguiente etapa comprendida entre 1950-1980 se caracteriza por la incontrolable expansión de la mancha urbana como consecuencia de la inmigración del entorno rural -100.000 nuevos residentes, principalmente de las sierras de Misantla y de Perote- y la aparición de nuevas colonias proletarias con viviendas precarias. En solo treinta años, la población se multiplicó 2,6 veces y su extensión casi se triplicó (Ayuntamiento de Xalapa, 2019: 29).

Las últimas cuatro décadas corresponden a procesos de expansión con menor densidad, pero de mayor expansión espacial. Cabe señalar que las tendencias de expansión urbana han privilegiado los espacios de topografía más suave 
hacia el Sureste, mientras hacia el Oeste es de menor intensidad. De acuerdo a datos de INEGI y del estudio de Robledo (Robledo et al. 2016), actualmente la zona metropolitana de Xalapa presenta una tasa de expansión en su mancha urbana del 2,5\% anual, mientras que su población crece un 1,8\% al año. En el período de 30 años entre 1980 y 2010, la ciudad de Xalapa duplicó su número de habitantes, al pasar de 212.769 habitantes a 457.614. En el mismo tiempo, la superficie urbana pasó de 917 hectáreas a 5.977, lo que equivale a un incremento de 8,64 veces en un período de 30 años. El crecimiento de la ciudad se ha extendido a los municipios vecinos de Banderilla, Emiliano Zapata y Tlalnelhuayocan, conformando una gran área conurbada que en 2010 sumaba una población de 666.500 personas y alcanzaba una extensión de 6.866 hectáreas en 2017.

Esta dinámica de expansión urbana ha ocurrido a costa de las áreas verdes suburbanas - bosques y selvas- y de terrenos agrícolas - potreros y cafetales, principalmente-, donde continúa la especulación con tierras que acaban convirtiéndolas en zonas habitacionales marginadas y fraccionamientos campestres. Cabe agregar que el crecimiento desordenado de la mancha urbana en las últimas décadas ha sido acompañado por una planificación municipal deficiente y ha provocado grandes riesgos y daños ambientales. Se han construido zonas habitacionales en lugares vulnerables a deslaves e inundaciones, se instauró la práctica de entubamiento de ríos urbanos y la contaminación de casi todos los cuerpos de agua como consecuencia de la ausencia o el mal funcionamiento de drenajes y plantas de saneamiento. Como otras ciudades del país, Xalapa también se ha vuelto escenario de inseguridad y violencia, además de problemas de vialidad, contaminación auditiva y visual, y desaparición de pequeños comercios a causa de competencia de plazas comerciales, entre otras problemáticas. Es una ciudad que se ha transformado drásticamente en los últimos 40 años y necesita soluciones creativas a su mal desarrollo.

Actualmente Xalapa es un escenario dinámico donde el modelo de desarollo convencional coexiste con un amplio abanico de acciones encaminadas a crear alternativas de vida sustentables y del buen vivir. La periferia rural suele ser la principal referencia para estas propuestas, inspira a aprender de ella y a cuidarla como reducto de buen vivir. 
FiguRA 1. LOCALIZACIÓN DE LA ZONA DE ESTUDIO: LA CIUDAD DE XALAPA Y LA DISTRIBUCIÓN DE las islas del Área Natural Protegida ArChipiélago de BosQues y Selvas de Xalapa

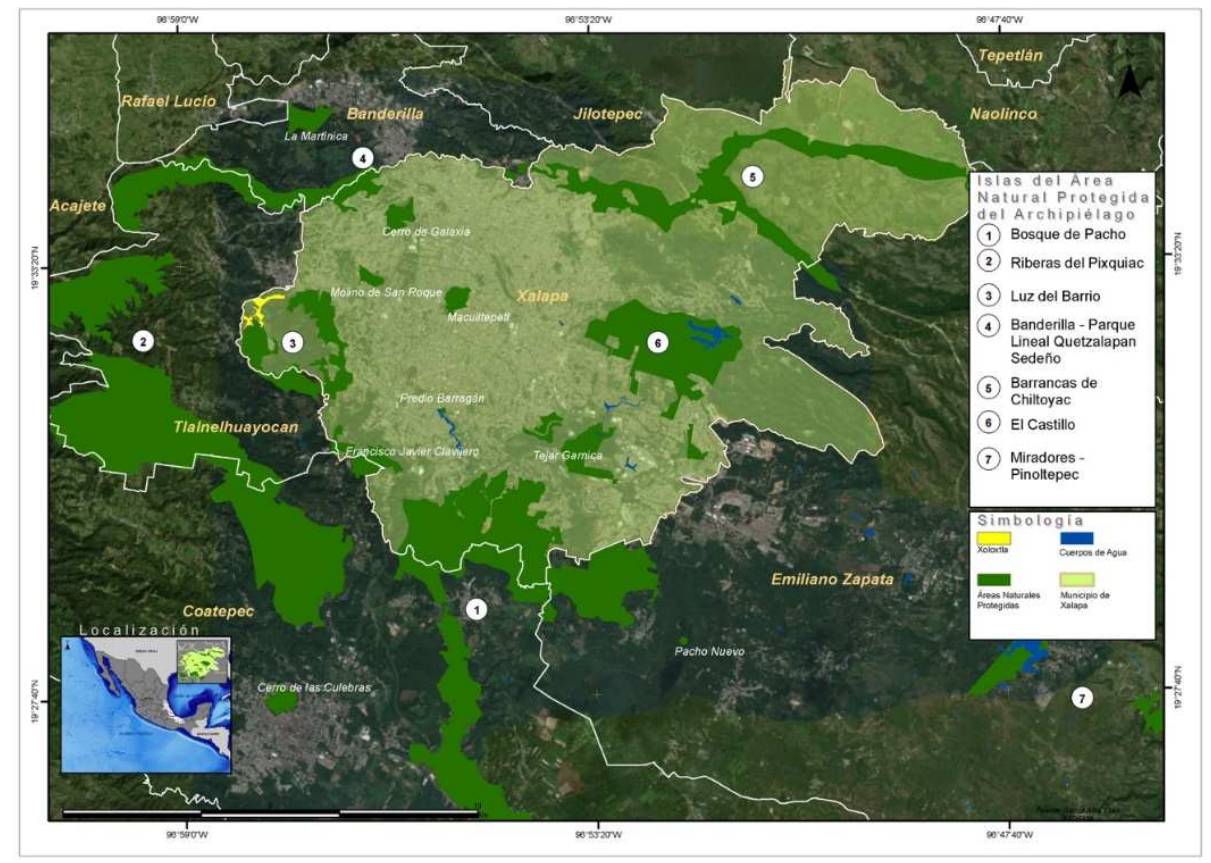

Fuente: elaboración de Elías García Alba, 2020.

\section{LA PERIFERIA DE LA CIUDAD COMO REDUCTO DE BUEN VIVIR}

A diferencia del área urbana, la Xalapa rural y sus alrededores son ricos en agua, bosque, saberes campesinos, modos de producción tradicional y vida comunitaria. Históricamente, las actividades productivas en esta zona oscilaban entre el cultivo de la milpa como sustento principal de las familias, la ganadería y el cultivo de café. Actualmente, estas formas rurales de producir y vivir están desapareciendo bajo la mancha urbana y la crónica crisis del campo que obliga a la gente a buscar otras fuentes de sustento. Al mismo tiempo que los antiguos habitantes de estas tierras deciden, bajo presiones del mundo moderno, convertirlas en mercancía y rentarlas como parcelas para cultivos tecnificados ${ }^{1} \mathrm{o}$ venderlas como lotes habitacionales, en amplios sectores de la población crece la consciencia del valor del medioambiente, de los saberes campesinos y formas

\footnotetext{
${ }^{1}$ Recientemente se introdujo el cultivo de la papa en parcelas rentadas a los agricultores foráneos. Este cultivo se realiza con el uso excesivo de tóxicos, con efectos nocivos en la salud de los ecosistemas y de los consumidores.
} 
de producción tradicional. Las zonas periurbanas se convierten en trincheras para la defensa de producción agroecológica, la economía familiar y la autonomía local, del medio ambiente y del buen vivir. A continuación, ofrezco algunos ejemplos para señalar la importancia de las zonas rurales contiguas a la ciudad de Xalapa para la sustentabilidad y el buen vivir local, sin pretensión de agotar este rico tema.

Considerando la flora, Xalapa es uno de los municipios más ricos y diversos del Estado de Veracruz. Los principales ecosistemas de Xalapa son el bosque mesófilo de montaña, el bosque de encino y la selva baja caducifolia. El bosque mesófilo de montaña, pese a su muy reducida distribución geográfica -presente sólo en el 0,7 \% del territorio nacional- es el ecosistema relevante, ya que alberga la mayor diversidad de especies de flora y fauna por unidad de superficie, además de que el 34,8\% de su flora es endémica de México. Además de la riqueza y la abundancia de especies vegetales, este ecosistema provee de servicios ambientales como captura de carbono, conservación del suelo y servicios hidrológicos muy importantes (Williams-Linera, 2007). Para conservar esta riqueza que aún rodea a la ciudad, en 2015 se decretó una nueva Área Natural Protegida (ANP) llamada Archipiélago de Bosques y Selvas de la Región de Xalapa. La ANP otorga estatus protegido a las áreas verdes discontinuas -islas- que forman un cinturón alrededor de la ciudad de Xalapa, con el afán de proteger los ecosistemas y los servicios ecosistémicos de los que depende la calidad de vida de los habitantes de la urbe. Esta medida jurídica intenta controlar el crecimiento de la ciudad y frenar la destrucción de áreas verdes y rurales (Fondo Ambiental Veracruzano et al., 2018).

Cabe subrayar la estrecha relación entre algunas actividades productivas tradicionales con la conservación y restauración de la biodiversidad de los ecosistemas. La región central de Veracruz, incluyendo áreas inmediatas a Xalapa, se considera una de las más importantes productoras de café arábigo de altura cultivado bajo sombra. El sistema tradicional de cultivo de café es un sistema agroforestal que se adapta y se asemeja a la estructura y composición del bosque. Los sistemas agroforestales -llamados a veces "bosques comestibles - son formas de manejo heredadas de los pueblos indígenas del trópico mexicano y adaptadas a nuevos cultivos. El sistema rústico del café se caracteriza por el uso bajo o nulo de agro-químicos y labores agrícolas mínimas, la conservación de especies arbóreas nativas, el enriquecimiento con especies maderables y frutales, la alta biodiversidad y el uso de mano de obra familiar. Los cultivos arbolados como las fincas de café bajo sombra son refugios para diversas especies de flora y fauna. De acuerdo a los investigadores, la importancia de fomentar plantaciones de café con 
sombra radica en que pueden constituir estrategias para la conservación de la biodiversidad regional (Moguel, Toledo, 1996).

La actividad cafetalera ha enfrentado muchas crisis a consecuencia del control global de los precios de café, las plagas, la tecnificación de los cultivos que consiste en el empleo de variedades especializadas e, incluso, genéticamente modificadas-, la transformación de la estructura tradicional en monocultivos sin sombra, la aplicación de fertilizantes inorgánicos y el control químico de plagas, produciendo cambios drásticos en el sistema natural que soporta la producción. En la región de Xalapa, los cafetales han sido de las áreas más acechadas por las empresas inmobiliarias y se han estado convirtiendo en fraccionamientos habitacionales y plazas comerciales. Como resistencia a estas tendencias, algunos investigadores y productores impulsan iniciativas cafeticultoras sustentables en términos ecológicos y económicos, que consisten en la transferencia de conocimientos y tecnologías que permitan mantener los agro-ecosistemas cafetaleros saludables y mejorar los beneficios de los productores, principalmente buscando su certificación orgánica y mercados de comercio justo (Contreras-Hernández, 2010).

La periferia de Xalapa cuenta con varias comunidades tradicionales donde aún prevalece el policultivo de la milpa. La milpa es propia de Mesoamérica, es patrimonio biocultural de los pueblos originarios y la base de la soberanía alimentaria de las actuales comunidades campesinas de México. Consiste en un agro-ecosistema diversificado de plantas que proveen la base de la alimentación tradicional de la región, donde el maíz, el frijol y la calabaza son las principales, pero no únicas, plantas comestibles cultivadas, además de otras semi-domesticadas y silvestres que se aprovechan en la parcela. A menudo es señalado el carácter anticapitalista del sistema de la milpa y su relación con el buen vivir, pues su lógica es la misma (Bartra, 2010). Esta estrategia de subsistencia, basada en el conocimiento ancestral, tiene como eje la apropiación de los recursos y de la biodiversidad del espacio de vida en forma plural y sustentable. La milpa está conectada con muchos aspectos de la vida familiar y comunitaria, tanto materiales como simbólicos. Su característica es la diversidad puesta en juego: semillas criollas, tecnologías agrícolas tradicionales, formas de trabajo, productos que se obtienen a lo largo del ciclo agrícola y diversidad culinaria (Valderrama-Rouy, 2017: 95-110).

La práctica de la milpa tradicional se ve amenazada por las tendencias mundiales y regionales, especialmente a partir de la revolución verde que trajo la tecnificación de la agricultura y la dependencia del campesino de los paquetes tecnológicos y, más recientemente, por la amenaza de contaminación transgénica 
y privatización de las semillas. Estas dificultades, aunadas a bajos precios y a falta de apoyos para los productores, han empujado a los campesinos milperos locales a ir abandonando poco a poco sus parcelas y a dedicarse principalmente a la albañilería. En escala del país, la milpa y el maíz se convierten en el símbolo de la defensa de la autonomía de los pueblos, su soberanía alimentaria y el buen comer, promovidos en un movimiento con participación de campesinos, activistas y académicos. Una de las estrategias de esta lucha son las Ferias de la Milpa organizadas en varios estados del país. En la región de Xalapa, la Feria de la Milpa se realiza anualmente desde 2016 en el pueblo de Rancho Viejo, localizado a 3 kilómetros de la ciudad, para visibilizar la importancia de este patrimonio biocultural y promover un diálogo de saberes entre campesinos, académicos y consumidores para la defensa y el mejoramiento de la milpa en términos agro-ecológicos.

FIGURA 2. Río PIXQUIAC

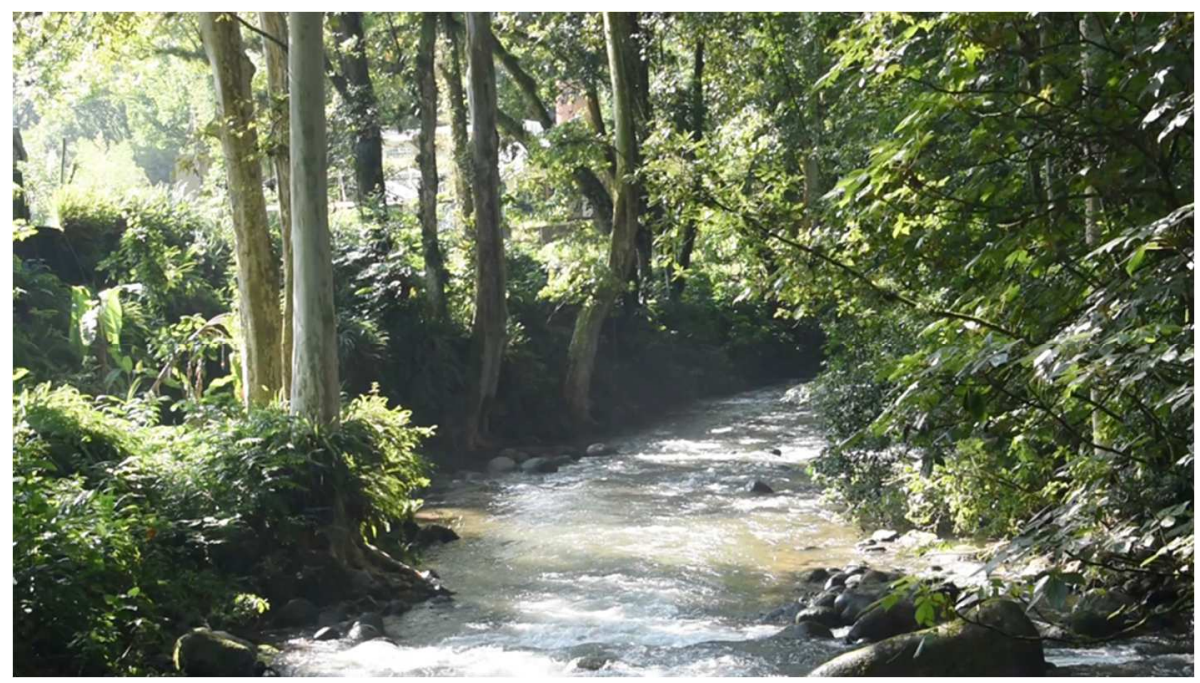

Fuente: fotografía de la autora.

La periferia de Xalapa es también un área de producción de quesos, de cultivo rústico de hortalizas y de cría de aves de corral que abastecen los mercados locales. En las últimas dos décadas fue introducida la cría de trucha arcoíris alimentada por la corriente del río Pixquiac, el único río todavía limpio en la zona; esta actividad ha motivado a los productores a defender el río contra la contaminación y la extracción excesiva de agua. Las actividades productivas, como las que mencionamos, fortalecen el arraigo territorial y el cuidado del medioambiente, resistiendo y fortaleciéndose gracias a la participación de la sociedad civil. 
Entre ellas, la asociación civil SENDAS ha jugado un papel importante en la promoción de proyectos comunitarios orientados a la producción sustentable y conservación de la cuenca del río Pixquiac (Paré, Gerez, 2012).

\section{"LA CIUDAD QUE QUEREMOS VIVIR Y EL CAMPO QUE QUEREMOS RECUPERAR"2}

Para visibilizar el rol activo de la ciudadanía en la construcción de las alternativas en la zona, a continuación describo algunas iniciativas de autogestión afines al buen vivir. La región de Xalapa -tanto su área urbana como la rural-es un campo fértil donde florecen trabajos encaminados a la sustentabilidad y al buen vivir con un rostro local y bio-regional. El campo de acción incluye entornos urbanos, periurbanos y rurales, y se practica desde la autogestión ciudadana o en vinculación con la academia. Entre estas acciones encontramos las orientadas a la defensa del medioambiente y de la agro-diversidad, los bienes comunes y el territorio, la promoción de eco-tecnologías, el buen comer y la procuración de la soberanía alimentaria, la economía solidaria, la justicia ambiental y el buen vivir. Surgen huertos urbanos, círculos de salud, centros culturales, casas comunitarias y proyectos de arte con sentido social.

En esta tarea convergen diversos actores que encuentran espacios de colaboración. Un lugar especial en esta configuración de colectivos lo ocupan las redes ciudadanas, que gracias a su estructura abierta y carácter incluyente resultan muy dinámicas y propositivas.

Entre las redes locales que convergen con la perspectiva del buen vivir están las relacionadas con la agro-ecología urbana y los mercados solidarios. Recordemos que la producción agro-ecológica consiste en la producción a pequeña escala y sin químicos, aprovechando los recursos locales, como las semillas y el agua, y haciendo uso de prácticas sustentables de producción. En la región de Xalapa operan al menos dos redes dedicadas al fomento de la producción de alimentos en hogares, centros laborales y espacios públicos, poniendo el mayor énfasis en las personas, aprovechando sus experiencias y promoviendo que se compartan conocimientos, semillas y alimentos sanos. La Red Ciudadana de Agricultura Urbana y Periurbana de Xalapa opera como un proceso itinerante dentro del espacio urbano-periurbano donde las personas interesadas aprenden sobre diferentes aspectos y técnicas de la producción agro-ecológica a partir de la práctica,

\footnotetext{
${ }^{2}$ El título de este apartado obedece a una de las consignas pronunciadas por los integrantes de la Red de Custodios del Área Natural Protegida en Xalapa.
} 
intercambio de experiencias y la reciprocidad. La Red de Huertos Escolares y Comunitarios constituye otra iniciativa local donde participan escuelas y huertos comunitarios. Por medio del aprendizaje colaborativo e intergeneracional, la red promueve la integración de saberes prácticos agro-ecológicos a los procesos educativos, así como el cuidado del entorno, la salud integral y la creación de comunidades solidarias. La red realiza regularmente tequios -trabajo colaborativo y recíproco-, talleres y eventos como el Festival de la Cosecha.

La producción agro-ecológica es apoyada por redes informales de consumidores conscientes y solidarios. Los mecanismos de comercialización local varían desde las canastas de hortalizas -donde grupos de consumidores apoyan a pequeños productores adquiriendo a un precio justo su producción de manera constante-, iniciativas de trueque, uso de monedas alternativas como el tumin, o tianguis -o mercados- de productos orgánicos de la zona presentes en Xalapa y pueblos vecinos de Coatepec y Xico. Todos estos espacios, además de ofrecer alimentos sanos, integran actividades educativas y generan vínculos más allá de los comerciales. El Tianguis Agroecológico de Xalapa -TAX-, iniciado en el 2003, es uno de los espacios más emblemáticos. Nace con la intención de brindar a la sociedad un espacio en donde poder encontrar alimentos saludables, orgánicos y de producción local. La calidad de los productos comercializados aquí es garantizada en el proceso de certificación participativa, mediante visitas de consumidores, productores y expertos a las parcelas. La iniciativa favorece la recuperación de las especies nativas, promueve el consumo de alimentos sanos, locales y directos del productor, facilita el acercamiento entre el campo y la ciudad, propicia un encuentro directo entre productores y consumidores y permite compartir conocimientos y aprender. Una iniciativa nueva es el mercado de trueque de carácter itinerante que surge en 2018 y abarca varios municipios cercanos a Xalapa. Además de ser una forma de impulsar un modelo de producción y consumo regional sustentable, estas prácticas son una forma de crear comunidad (https://www.uv.mx/cosustenta/general/tian/).

Otro de los colectivos con objetivos y prácticas afines al buen vivir es la Red de Custodios del Archipiélago, cuyo surgimiento se remonta a la reciente creación de la Área Natural Protegida Archipiélago de Bosques y Selvas de Xalapa en 2015. La Red de Custodios es una iniciativa ciudadana conformada por un grupo heterogéneo de personas interesadas en cuidar sus espacios de vida a través de la participación plural en el manejo cuidadoso del territorio, con el objetivo de desarrollar procesos colectivos para la salvaguarda de esta ANP. Entre las líneas de acción de la red está observar, informar y vigilar acerca de todos los aspectos 
que promuevan u obstaculicen la conservación de estas áreas y, a la vez, impulsar la colaboración y la vinculación para realizar acciones concretas de gestión participativa del territorio. El colectivo se aboca a dar seguimiento al desempeño de instancias gubernamentales y privadas a fin de asegurar que estos organismos cumplan con las disposiciones del decreto. Busca también abrir espacios de diálogo y visibilizar los esfuerzos de la gente por defender su entorno natural y hacer la ciudad más habitable. La Red de Custodios se organiza a través de reuniones generales mensuales, comisiones para la atención de temáticas específicas y grupos motores locales de las diferentes islas que conforman el conjunto de la ANP (http://custodiosanpxalapa.org).

FiguRA 3. INTEGRANTES DE LA RED DE CUSTODIOS DE LA ANP DURANTE LA GIRA DE APRENDIZAJE E INTERCAMBIO DE SABERES POR LA ISLA BOSQUES DE PACHO, MAYO 2018.

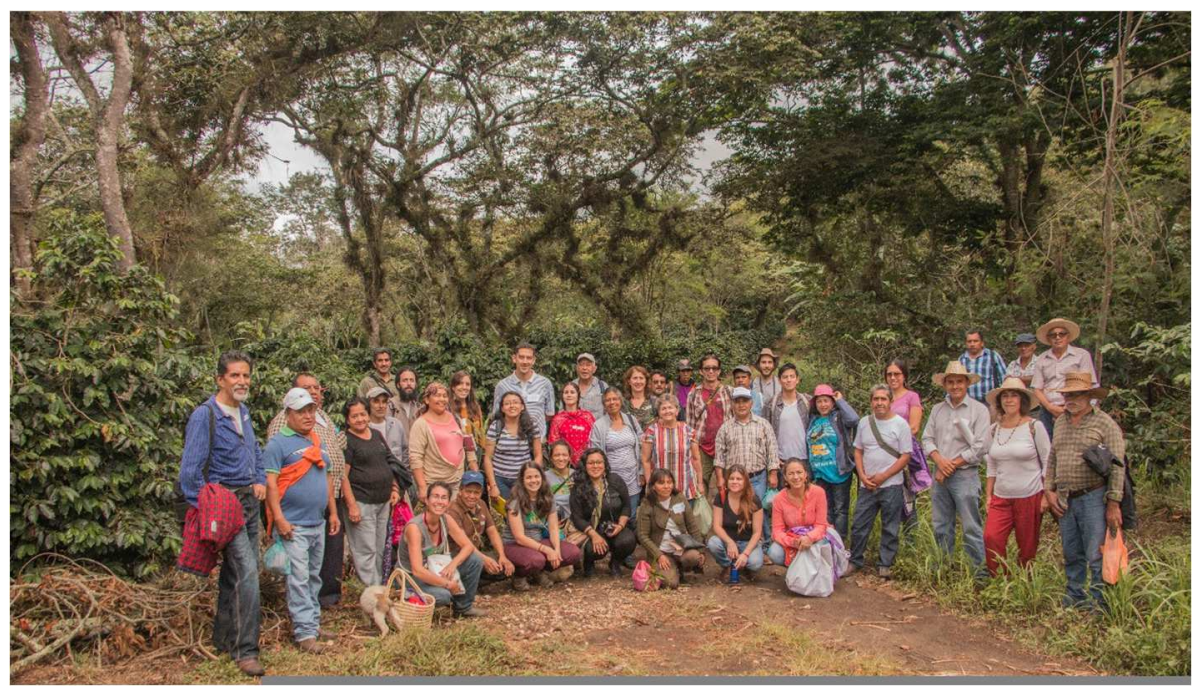

Fuente: fotografía de la Red de Custodios.

Esta somera aproximación al ámbito de colaboraciones apenas insinúa la creatividad y el compromiso de la ciudadanía con la causa de construir alternativas de vida desde el paradigma del buen vivir. Si existiera una agenda anual dedicada al tema que nos interesa, encontraríamos en ella una gran abundancia de talleres, charlas, festivales, ferias, encuentros, jornadas de trabajo en huerto, reforestación o bio-construcción, recorridos para la apreciación de la naturaleza, educación ambiental, promoción de la movilidad urbana alterna, encuentros de trueque de bienes y saberes, reuniones vecinales para procurar la seguridad de sus barrios y proyecciones de cine comunitario organizadas por estos colectivos de autogestión y abiertos a los que quieran participar. 


\section{INCURSIONES DE LA ACADEMIA EN EL BUEN VIVIR}

Cabe destacar el papel activo de la comunidad universitaria de Xalapa, académicos y estudiantes, en la gestión de estos espacios y actividades. Entre las universidades públicas con un fuerte compromiso institucional hacia procesos educativos dirigidos a la sostenibilidad y el buen vivir está la Universidad Veracruzana y su Coordinación Universitaria para la Sustentabilidad -CoSustenta-, algunas facultades, posgrados y centros de investigación. El Centro de Ecoalfabetización y Diálogo de Saberes -Ecodiálogo-, fundado en 2008, retoma este compromiso buscando generar conocimiento social y ecológicamente pertinente. El centro está dedicado a la investigación de frontera dirigida a producir estudios y prácticas trans-disciplinarias para la construcción de alternativas al desarrollo y a la transformación social hacia un futuro sostenible.

El nuevo currículo aplicado a la Maestría en Estudios Transdisciplinarios para la Sostenibilidad adscrita al Centro se basa en una propuesta pedagógica de re-aprendizaje trans-disciplinario, eco-alfabetización y diálogo de saberes. La trans-disciplinariedad representa una ruptura con el modo lineal de leer el mundo y ofrece un pensamiento apto para afrontar el reto de la complejidad mediante la articulación de los saberes. Estar ecológicamente alfabetizado significa pensar en términos de relaciones y encadenamientos a partir de una perspectiva sistémica y situar todo acontecimiento dentro de su relación de inseparabilidad respecto de su entorno cultural, social, económico, político y natural. El llamado diálogo de saberes es el diálogo del conocimiento científico y disciplinar con otras formas de saber cómo sistemas tradicionales y vernáculos de conocimiento, y se enfoca a la generación de conocimientos no ortodoxos y praxis transformadoras, pertinentes y dirigidas hacia las problemáticas locales y planetarias (Universidad Veracruzana, 2008).

Actualmente, en Ecodiálogo existen cuatro líneas de trabajo que abordan este reto desde diversas aristas. El eje investigativo de Creatividad Social y Comunidades Sostenibles se encamina a explorar relaciones entre estas nociones a partir del interés por encontrar formas de vida y visiones de mundo que permitan hacer frente al deterioro de las relaciones humanas, para lo cual se exploran formas de espiritualidad laica y tradiciones mesoamericanas. La línea de Manejo y Conservación de Recursos Bioculturales se orienta a diseñar estrategias y metodologías que sirvan para promover la conservación y la restauración productiva de recursos bioculturales, mediante sistemas agroforestales y silvícolas, así como el desarrollo endógeno local entendido como florecimiento. La tercera está cen- 
trada en la Sustentabilidad Humana para el Buen Vivir, donde se trabajan procesos de sustentabilidad humana y comunitaria, ecología organizacional-comunitaria y biomedicina sistémica. Finalmente, la línea de Epistemologías del Sur explora las posibilidades de recuperar la diversidad epistémica del mundo e integrarla en la creación de alternativas de vida más sustentables y justas, a escala local y desde procesos dialógicos en tiempos y espacios cotidianos. La inclusión creativa de los saberes del Sur, entendido como paradigma de lo que ha sido cegado, desacreditado y subyugado por la hegemonía, implica un desacuerdo radical con las asimetrías de poder existentes (Santos, 2009). Los fundamentos éticos y políticos de esta perspectiva pueden resumirse en tres postulados pronunciados por Boaventura de Sousa Santos: descolonizar el pensamiento y la convivencia, rebajar la mercantilización de la vida e integrar la diversidad en la creación de escenarios futuros.

FIGURA 4. TALLER COMUNITARIO PARA DOTAR DE NUEVA SIGNIFICACIÓN AL BUEN VIVIR A PARTIR DE LA EXPERIENCIA COMPARTIDA ENTRE LOS VECINOS DE LA ANP, LOS ACADÉMICOS

Y LOS ESTUdiANTES. XALAPA, INSTALACIONES DEL CENTRO DE ECOALFABETIZACIÓN Y DiÁlOGO DE SABERES, UNIVERSIDAD VERACRUZANA, MAYO 2016.

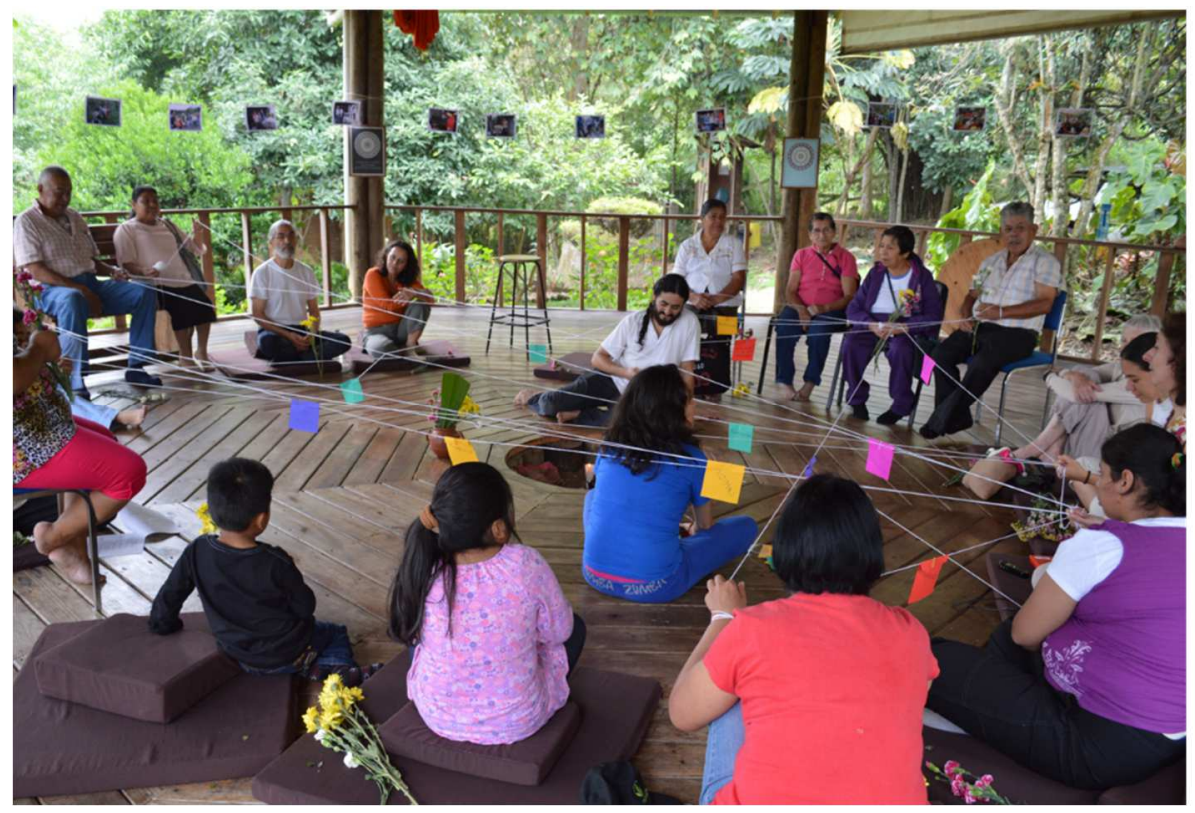

Fuente: fotografía de la autora.

Los proyectos gestionados desde el Centro, planteados como indagaciones colaborativas, involucran diversos sectores de la sociedad -comunidades de aprendizaje- incluyendo lugares en la periferia rural de Xalapa como Chiltoyac, 
Xoloxtla o Rancho Viejo. El proyecto Diálogo de saberes para el buen vivir nace en 2015 en el seno de la línea Epistemologías del Sur, y se concibe como un proyecto sombrilla para ensayar y nutrir diversas estrategias y acciones encaminadas a la sustentabilidad ecológica, social y humana en la periferia de la ciudad de Xalapa a mediano y largo plazo. Promover espacios de reflexión, dotar de nueva significación y recreación del buen vivir en los contextos vecinales de frontera entre la ciudad y el campo ha sido el objetivo principal de esta iniciativa, dando como principal resultado la reafirmación del arraigo territorial y el fortalecimiento del tejido social a partir de la convivencia en la localidad de Xoloxtla.

\section{XOLOXTLA, UN LUGAR PARA CUIDAR}

Xoloxtla es una pequeña localidad de 479 habitantes donde todos se conocen y se saludan. El lugar ha podido conservar sus características rurales y amplias extensiones de áreas verdes, principalmente de bosque de encino y pastizales, así como formas de organización comunitaria y actividades productivas vinculadas a la ganadería extensiva y a la producción de quesos a pequeña escala. Se localiza en la parte occidental del municipio, que hasta el momento se ha resistido con éxito al crecimiento de la mancha urbana gracias a la escasez de servicios básicos, la accidentada topografía y la renuencia de los habitantes a vender sus tierras. Desde el punto de vista del desarrollo municipal, este área se considera de las más marginadas de Xalapa: cuenta con una escuela primaria, un servicio de electricidad desde la década de los setenta, agua potable municipalizada y dos caminos pavimentados en los noventa. Debido a su alto valor para la protección de la biodiversidad y los servicios ambientales que provee a la ciudad, una parte de Xoloxtla hoy es parte del Área Natural Protegida del Archipiélago de Bosques y Selvas de Xalapa. También cuenta con vestigios arqueológicos de un centro ceremonial prehispánico que han sido poco estudiados (Beauregard-García, 1986).

Una gran parte de los habitantes de Xoloxtla pertenece a la población originaria, es propietaria de los terrenos y se concentra en pocas familias que se mantienen unidas, conservando algunas instituciones comunitarias tradicionales para la atención de los aspectos centrales de la vida colectiva en la localidad: abastecimiento del agua, mantenimiento de los caminos y organización de la vida religiosa. La dimensión espiritual es de gran importancia para el sostenimiento de la cohesión social y se expresa principalmente en los arreglos de la fiesta patronal de San José, la tradición de las Cruces de Mayo y la ayuda solidaria en 
casos de fallecimiento de algún vecino. Estos comités generalmente excluyen a los vecinos que no nacieron en el lugar.

El carácter rural de la localidad ha estado transformándose lentamente en campestre-residencial coexistiendo con el uso ganadero de poca intensidad. La mayoría de los propietarios foráneos compró lotes amplios, algunos mayores de 80 hectáreas, en las últimas cuatro décadas, como inversión a futuro o con fines de conservación contribuyendo, al menos hasta el momento, a mantener el carácter rural del lugar. Xoloxtla no ha experimentado aún los efectos de la expansión violenta de la mancha urbana que han sufrido otras áreas rurales de Xalapa. Sin embargo, su conurbación con las colonias populares ya es un hecho. Se empiezan a lotificar y vender algunos terrenos abriendo el camino a la construcción de fraccionamientos y a la urbanización de esta zona, que amenaza el equilibrio y la continuidad de este sistema socio-ambiental.

A lo largo de diez años de mi residencia en el lugar, de los cuales cinco transcurrieron en el marco de participación en iniciativas de indagación colaborativa con los vecinos, juntos identificamos áreas de riesgo y oportunidad para fortalecer saberes y prácticas locales hacia el buen vivir. El primer factor que amenaza Xoloxtla es la crisis del campo que estriba en la dificultad de los productores locales para mantener actividades productivas propias de la zona; el segundo es la presión inmobiliaria y la urbanización caótica de áreas verdes y con bajo poblamiento. A la vez pudimos constatar y visibilizar la vitalidad de importantes valores sociales, culturales y ambientales que se expresan en la riqueza de sus paisajes, saberes y formas de convivencia; bienes que son comunes y que convergen con la perspectiva del buen vivir. Es por ello que la tarea de crear espacios de reflexión colectiva sobre el buen vivir se convierte en un compromiso a largo plazo que requiere de estrategias para generar nuevos conocimientos y mecanismos comunitarios que impacten en la toma de decisión de los vecinos hacia el cuidado del lugar y de las relaciones.

\section{HACIENDO EL CAMINO AL ANDAR: ENSAYOS PARA LA SUSTENTABILIDAD} Y EL BUEN VIVIR

A continuación, comparto de manera resumida la sistematización de las principales etapas, actividades, circunstancias, logros y retos que se presentaron a lo largo del desarrollo del proyecto, que en su conjunto dan cuenta de la reconfiguración a partir de la experiencia. El ejercicio muestra claramente la evolución de una estrategia que nace desde la inconformidad personal, la esperanza y el compromiso, para irse alimentando de nuevas colaboraciones entabladas con 
diversos actores y colectivos locales; una estrategia reflexiva, recursiva y flexible, que "se hace al andar" y por lo tanto está sujeta al replanteamiento constante, a manera de ensayo (Morin et al., 2002).

Etapa I. Sembrando y dotando de nuevo significado la noción de buen vivir desde lo local: la proximidad vecinal y la implicación en procesos cotidianos ${ }^{3}$.

En la primera etapa nos abocamos a la tarea fundamental: reconocernos en el territorio y entre los vecinos. La estrategia se basó en reuniones vecinales itinerantes en casas de diferentes vecinos para conocernos mejor, la realización de caminatas grupales guiadas por personas locales de reconocido prestigio y profundo conocimiento del territorio y su historia, el trabajo colectivo para el bien común y el juego, procurando también contextos más formales como talleres de reflexión colectiva sobre las nociones del buen vivir y bienes comunes. La proximidad espacial facilitó la comunicación boca a boca, la asistencia a las reuniones y a las jornadas de trabajo, y la identificación de preocupaciones comunes en el territorio compartido. En el arranque del proceso ayudó el interés genuino de los vecinos en el cuidado del espacio de la comunidad, la convivialidad que caracteriza relaciones entre los habitantes, el arraigo de las instituciones comunitarias y la experiencia ancestral del trabajo colectivo en pro del bien común. La escasez de espacios públicos para la realización de actividades y de mecanismos que facilitaran la comunicación, inicialmente ayudó a proponer estrategias que nos acercaron, pero conforme el proyecto avanzaba estas condiciones resultaron ser un obstáculo para que nuestras acciones trascendieran.

En esta fase inicial logramos el reconocimiento de nuestra pertenencia al territorio compartido, acompañada por el reconocimiento mutuo en nuestras diferencias y semejanzas en cuanto al modo de habitar el lugar. Fue posible identificar preocupaciones y prioridades comunes y fortalecer la confianza entre los vecinos. Al mismo tiempo se evidenciaron nuevas necesidades centradas en la expansión de la red vecinal y el impacto de nuestras acciones y encontrar mecanismos de comunicación y convocatoria más eficientes. Como un logro emergente de esta primera etapa de acercamiento surgieron diversas acciones colectivas orientadas al cuidado de nuestros espacios cotidianos, como la limpieza de espacios abandonados y del bosque próximo a la localidad, la construcción de estufas ecológicas de leña en casas de los más necesitados organizada a manera de mano vuelta, y los talleres de verano para niñas y niños.

\footnotetext{
${ }^{3}$ En esta primera etapa el proyecto contó con el apoyo del programa PROMEP-NPTC. Las siguientes etapas se realizaron prácticamente sin financiamiento institucional.
} 
El espíritu colectivo, la experiencia de las personas de la comunidad en la organización y realización de trabajo colectivo, y el involucramiento desinteresado de los vecinos- profesionistas fueron los factores que favorecieron el proceso. En cambio, los patrones de asistencialismo, clientelismo y co-dependencia arraigados fuertemente en algunos sectores de la población dificultaron el diálogo. Las actividades conjuntas para el bien común lograron visibilizar una diversidad de saberes tácitos y de capacidades personales de los participantes, así como la capacidad de auto-organización y de creatividad social en la solución de problemas. Este aprendizaje colectivo se generó a partir de la colaboración, afirmando los valores y las formas de convivencia locales tales como solidaridad, reciprocidad, respeto y cuidado del entorno. Estas acciones apenas insinuaron la existencia de múltiples posibilidades, donde el reto consiste en procurar espacios permanentes para la creatividad social y el cultivo del buen vivir en comunidad (Paradowska, 2017).

Etapa II. Ampliando la participación: nuevos actores, espacios y herramientas.

En respuesta a esta necesidad, apostamos por la inserción del eje del buen vivir en procesos formativos de algunas instituciones educativas públicas de la zona, tanto a nivel básico como superior. El eje se introdujo en experiencias educativas electivas y complementarias a nivel de licenciatura y maestría, aunque también permeó algunas actividades de vinculación con la participación de estudiantes, como el diseño, la facilitación y la sistematización de actividades de vinculación en la zona. A manera de acuerdos con tres escuelas, se realizaron Talleres de Sensibilización Ambiental y Talleres de Arte y Buen Vivir, generando un marco de colaboración muy fructífera entre universitarios, niños y adolescentes del área rural, involucrado también a los maestros e integrantes de algunos colectivos de autogestión. Observamos que, pese a sus limitaciones, estos espacios formales también ofrecen un ambiente favorable para seguir sembrando la noción del buen vivir en las jóvenes generaciones y debemos asegurar la continuidad de estas colaboraciones a mediano y largo plazo (Paradowska, 2018).

Simultáneamente, descubrimos la pertinencia de la inclusión de nuevas herramientas y lenguajes para fortalecer estos procesos. En los talleres nos abocamos a incentivar la creación colectiva de narrativas audiovisuales, canciones y carteles con temática del buen vivir y del cuidado del territorio. Incluimos también la producción de video-documentales con temáticas locales alusivas al buen vivir, con la participación de los habitantes del lugar como protagonistas (Guigui et al., 2019; Rodríguez et al., 2019). El diálogo inter-actoral e intergeneracional 
que se dio en el marco de los procesos creativos ayudó a la revitalización de saberes bioculturales y al fortalecimiento del arraigo entre los involucrados. Al mismo tiempo, las actividades creativas contribuyeron a la generación de productos de difusión, cuyas muestras en diversos foros están acercando el mensaje a un público más amplio, promoviendo intercambios y alianzas para futuras colaboraciones.

FiguRA 5. DiÁLOGO DE SABERES ENTRE LOS ALUMNOS DE LA ESCUELA TELESECUNDARIA, LOS ESTUDIANTES Y LOS CAMPESINOS EN EL MARCO DE LOS TALLERES DE ARTE Y BUEN VIVIR. RANCHO VIEJO, JUNIO 2017.

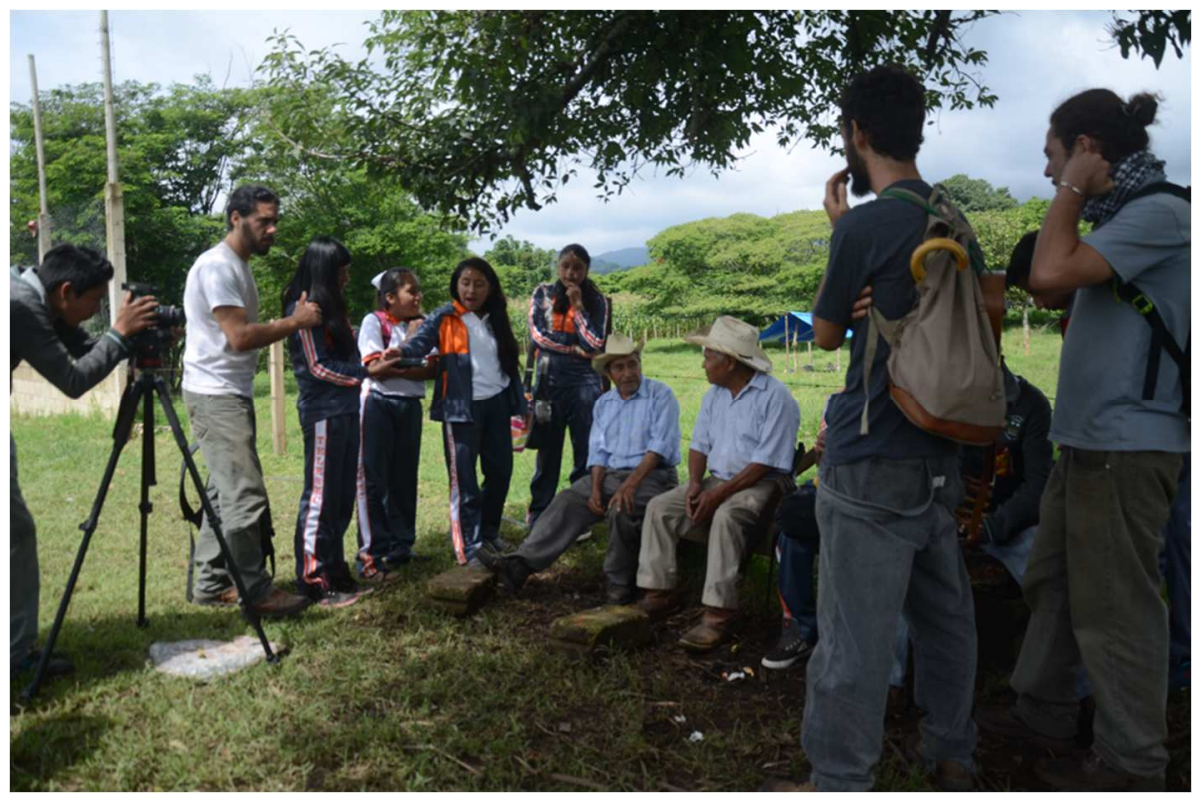

Fuente: fotografía de la autora.

Etapa III. Tejiendo redes de colaboración en el territorio.

La colaboración más significativa para el proyecto proviene del acercamiento con la Red de Custodios del Área Natural Protegida de Bosques y Selvas de la región de Xalapa que nos vinculó con otros colectivos de la región, como Desarrollo Sustentable del Río Sedeño y Caja Mágica. La colaboración se ha dado naturalmente gracias a múltiples convergencias, como la de compartir el territorio y el enfoque de trabajo, además de empatías personales. La Red de Custodios es un grupo abierto, diverso, activo y rico en saberes y experiencias, cuya dinámica de colaboración ofrece un escenario de posibilidades casi infinitas. La retroalimentación y el fortalecimiento han sido recíprocos y han fructificado con la realización de actividades conjuntas con un mayor impacto, como talleres y festi- 
vales, además de ofrecer un marco idóneo de capacitación en metodologías participativas y de intercambio de experiencias (Hensler et al., 2019). La colaboración con la Red propicia un ambiente estimulante para la gestión de nuevos proyectos con enfoque del buen vivir en esta área.

Entrar en complejas dinámicas de trabajo colaborativo conlleva muchas satisfacciones, pero también dificultades y los riesgos propios de los procesos de autogestión. Continuar enriqueciendo el proceso, sin perder de vista los principios que nos convocan, emerge como un nuevo reto ético y práctico en nuestro quehacer compartido.

FIGURA 6. GIRA DE APRENDIZAJE E INTERCAMBIO DE EXPERIENCIAS EN LA ISLA BARRANCAS DE ChILTOYAC, ORGANIZADA POR LA RED DE CUSTODIOS EN El MARCO DEL CURSO de Metodologías Participativas para la Cogestión del Territorio. Xalapa. Junio 2018.

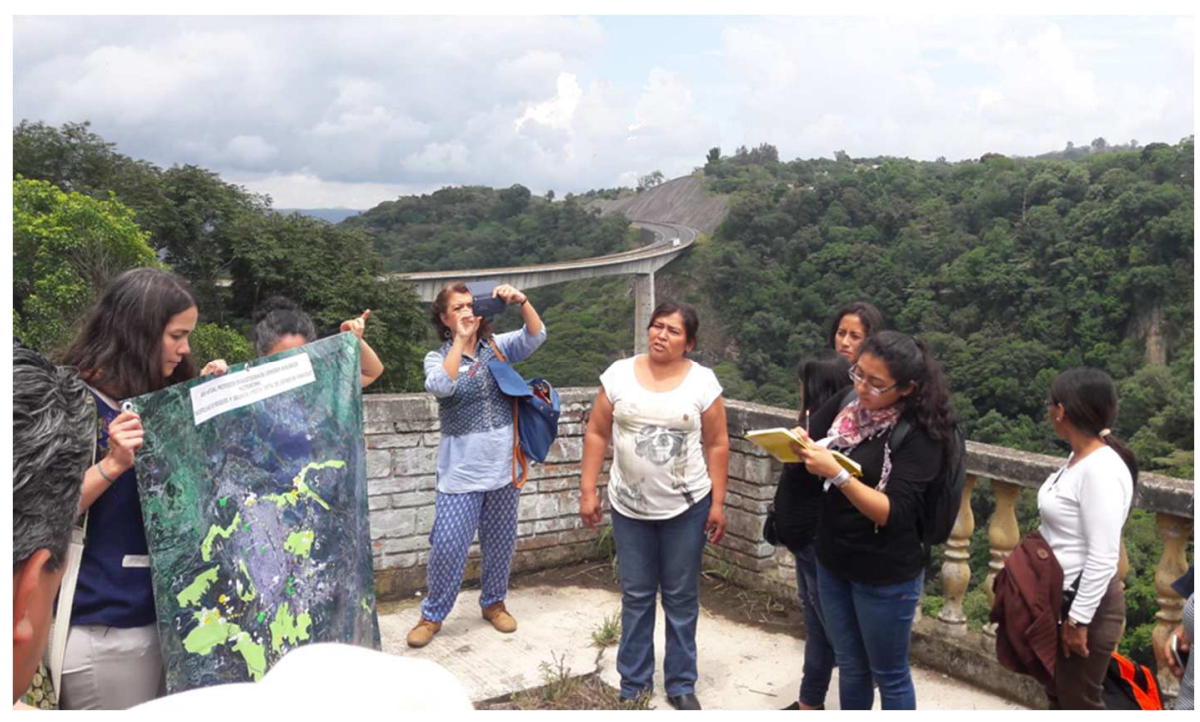

Fuente: fotografía de la autora.

\section{APRENDIZAJES PARA UN NUEVO COMIENZO}

La noción del buen vivir nos ha ayudado a emprender un viaje transformador del que "se regresa 'con nada' para enseñar de la experiencia"; como dice la epopeya de Gilgamesh, "se regresa del viaje para empezar otro" (Gilgamesh, citado por Morin et al., 2002: 16). El aprendizaje del viaje que implicó la participación en las iniciativas encaminadas al buen vivir nos ayuda a acotar y actualizar las respuestas sobre para qué, para quién, desde dónde, cómo y porqué yo. Usualmente, se recomienda colocar estas preguntas antes de empezar con la aplicación 
de las metodologías participativas (Hernández, 2010), pero aquí las respondemos en el contexto de aprendizajes que pueden alimentar nuevas búsquedas.

La respuesta a la primera de estas preguntas, para qué, podría expresarse en algunas frases aparentemente marchitas, como: la paz, una vida sin violencia, la armonía, la felicidad, salvar el planeta o re-encantarnos con la vida; frases que cobran relevancia porque estas cualidades son cada vez más escasas o lejanas de las realidades que vivimos. No por ello están condenadas al olvido, sino al contrario, deben recuperar su lugar y convertirse de nuevo en principios de nuestra vida colectiva.

En el marco del proyecto Diálogo de Saberes para el Buen Vivir la pregunta para qué nos llevó a descubrir que el cuidado de la relación es el principal objetivo, al mismo tiempo que el camino -el qué y el cómo- para el surgimiento de la comunicación horizontal, la escucha y la confianza que posibilitan cualquier cambio hacia el buen vivir a futuro. La relación empática, recíproca y solidaria es el principio estructurador de los mundos alternos con respecto al mundo moderno occidental fundado en la separación y la dominación, y el cultivo de estas relaciones armoniosas es el cimiento del buen vivir. Los "mundos" o las "ontologías relacionales" (Escobar, 2016: 16-19) se basan en el reconocimiento de que todo existe "en relación y gracias a" lo demás. En el mismo tenor, el cuidado esencial planteado por Leonardo Boff como un "modo-de-ser-en-el-mundo", "una forma de existir y coexistir, de estar presente, de navegar por la realidad y de relacionarse con todas las cosas del mundo" (Boff, 2002: 74), no es antropocéntrico ni patriarcal, sino " "el-modo-de-ser' que rescata nuestra humanidad más esencial" (Boff, 2002: 85). El cultivo de la relación con el entorno implica situarnos con firmeza en un lugar particular.

Como consecuencia de lo anterior es que los entornos locales y las redes vecinales se colocan como los más apropiados para trabajar. De acuerdo a Arturo Escobar, redescubrir la escala local es la respuesta al sesgo universalista y hegemónico del poder y del saber colonial presente en la ciencia, instituciones y políticas globales, regionales o nacionales. El regreso al lugar significa pensar en clave de lo local y posibilita reconstruir mundos relacionales. El buen vivir, pues, implica recomponer nuestras vidas desde la pertenencia: social, territorial y planetaria.

El para quién significa aquí la inclusión y el cuidado de todo y todos los que componen los mundos relacionales, en especial de lo que ha sido explotado o marginado por el paradigma moderno, incluyendo el cuerpo, lo espiritual y la naturaleza. En el paradigma del buen vivir, la naturaleza se coloca como un sujeto con valor intrínseco, como Madre Tierra. Esta perspectiva no es antropo ni socio- 
céntrica, con lo que difiere de la sustentabilidad que, pese la diferencia, es su compañera y aliada. El imaginario del buen vivir se acerca sin duda al imaginario sensible de la ecología profunda de Leonardo Boff: "El clamor de los pobres se une al grito de la Tierra" (Boff, 2011).

Lo último nos remite a la pregunta desde dónde. Nuestra práctica nos enseña que debemos construir alternativas desde marcos informales, cotidianos y de convivencia tanto para el planteamiento como para el desarrollo de las estrategias en comunidad. Esto ocurre y se enriquece en las movilizaciones espontáneas que emplean la creatividad y la auto-organización. Coincidimos con las ideas de Tomás Rodríguez Villasante y los Ilusionistas Sociales, quienes señalan que en el sistema hegemónico, dominado por el interés del Estado o del Mercado donde las personas son reducidas a consumidores y espectadores, "los tiempos y espacios cotidianos" parecen ser las últimas grietas de autonomía, donde es posible "que la gente sea protagonista de su vida", donde puede "crecer como personas a través de las relaciones con los demás, encontrándonos unas personas con otras, y así todas las formas posibles de enredarse" (Encina, Ezeiza, s/f). Raúl Zibechi nos habla de "espacios de participación" como "espacios horizontales, dialógicos, flexibles, cambiantes, autónomos, rebeldes, creativos, integrales e integradores de la diversidad, polifuncionales, sin estructuras fijas" (Zibechi, 2008, citado por Encina y Ezeiza, s/f). De la misma manera que el espacio, se trata de rescatar el tiempo para que sea vivido y construido colectivamente. El cambio social es posible desde la vida cotidiana, pues es allí donde las alternativas pueden ser articuladas por y para sus sujetos, a partir de los saberes cotidianos y de convivencia (Rodríguez-Villasante, 2014; Encina, Rosa, s/f).

Desde dónde también implica la diversidad como condición para que lo nuevo emerja. La diversidad de voces, miradas, iniciativas y espacios que participan en la recreación del buen vivir en Xalapa nos permite aprovechar de una manera sensible, dialógica y creativa la riqueza de saberes y experiencias para poder tejer fino a la hora de planear estrategias y acciones. La diversidad del presente posibilita la emergencia de alternativas a futuro, nos explica Boaventura de Sousa Santos en su Sociología de las emergencias (Santos, 2009). Para que la diferencia no se traduzca en asimetrías de poder, precisa renunciar a los privilegios y a la imposición de soluciones. En un contexto dialógico donde todos nos asumimos como diferentes, pero a la vez dispuestos a dialogar con la otredad y contribuir al bien común desde lugares diferentes, buscamos ser complementarios más que antagonistas. 
El principal aporte de la experiencia que aquí compartimos abona justo este aspecto de trabajo colectivo en red que podemos colocar como una respuesta a la pregunta por el cómo. Conscientes de que el buen vivir es una tarea colectiva y no individual o acotada a un minúsculo grupo vinculado a algún proyecto específico, el objetivo de colectivizar la tarea se ha venido reafirmando y cobrando cada vez mayor importancia. La inclusión, el diálogo horizontal y el co-diseño emergen como principios y como prácticas que nos recolocan constantemente dentro de una red colaborativa, donde ser sujeto significa a veces tomar un rol activo y a veces se limita a la escucha y a la vigilia. A veces nos toca estar en la posición de retaguardia, en el sentido que le confiere Boaventura de Sousa Santos en el contexto del protagonismo de los movimientos sociales -la vanguardia-, donde el papel del académico se concentra en el acompañamiento y el cuidado del proceso.

Finalmente, la perturbadora pregunta por qué yo nos remite a la comprensión del significado del sujeto como el que confiere sentido al conocimiento y actúa con responsabilidad ética. En el escenario que brevemente revisamos, la acción se generó desde la inconformidad y desde un compromiso personal que se transformó en tarea colectiva de nosotros. Reconocerse como sujeto significa asumirse como parte del problema y, por lo tanto, de la solución, se expresa en la búsqueda de una implicación que va más allá del marco formal del proyecto, desborda los tiempos y espacios cotidianos e involucra una apertura al diálogo y a la experiencia como la principal vía para la construcción de un conocimiento pertinente.

\section{UNA UTOPÍA LATINOAMERICANA QUE NOS HACE CAMINAR}

Las reflexiones que acabo de compartir podrían inscribirse en lo que Boaventura de Sousa Santos ha llamado sociología de las ausencias, sociología de las emergencias y el trabajo de traducción (Santos, 2009: 98-159). Desde una participación implicada se intentó aquí visibilizar, legitimar y fortalecer las iniciativas no-hegemónicas que abrevan en la diversidad epistémica del mundo local de los académicos, los activistas sociales y los habitantes-vecinos que interactúan para una causa socio-ambiental común. El paradigma de desarrollo toma el lugar de la teoría general que se impone sobre otras lógicas y ciega las alterativas, mientras que el conjunto de los actores involucrados corresponde a la particular constelación de lucha que, como lo define el autor, "es el resultado de una conjugación de tiempos, ritmos y oportunidades". En este contexto diverso y dinámico, lo que nos une y permite la inteligibilidad necesaria para ejercer la traduc- 
ción es la zona de contacto, identificada por el autor con los "campos sociales donde diferentes mundos de vida normativos, prácticas y conocimientos se encuentran, chocan e interactúan" (Santos, 2009: 144). En nuestro caso, esta zona de contacto es la preocupación común por el territorio que compartimos, que se articula mediante el cuidado del medioambiente, el fortalecimiento de las prácticas agro-ecológicas y del tejido social a nivel local y bio-regional. Los matices de esta preocupación compartida reflejan claramente la idea del buen vivir, subyacente a estas acciones colaborativas.

El interés en buen vivir es amplio y proviene no sólo de la negación de un modelo civilizatorio sino también de la afirmación de los valores universales presentes en la experiencia de toda la Humanidad que rebasa el nicho de los pueblos indígenas de la actual Latinoamérica. En la era del Antropoceno y la crisis planetaria, las preocupaciones comunes traspasan las fronteras geográficas, culturales y sociales, demandando fortalecer nuestras formas no-dualistas de ver y vivir el mundo. De allí, el potencial civilizatorio de las cosmovisiones no-modernas y de las epistemologías del Sur en la construcción de un nuevo orden. Este orden empieza por reasumir que "nosotros no somos dueños de la tierra, nosotros pertenecemos a ella" y, por ello, necesitamos "restablecer una relación de equilibrio con toda forma de existencia y de armonía con los ciclos de la Madre Tierra", donde "lo primero en nuestras decisiones es la Madre Tierra, la comunidad, después la familia y luego nosotros mismos como individuo" (Huanacuni Mamani, 2010: 74).

En tiempos de crisis global, los pueblos originarios de los Andes y también los de Mesoamérica, con muncha lucidez y pertinencia nos orientan sobre cómo debe ser el arte de vivir bien (Huanacuni Mamani, 2010; Paradowska, Fabre, 2017). Lo ofrecen como una propuesta al mundo atravesado por la crisis, donde sus interlocutores lo recibimos como un regalo que inspira nuestras propias búsquedas dentro de las circunstancias de vida que nos toca vivir. En este trabajo he retomado esta invitación con el fin de dotar de nuevo significado la noción de buen vivir desde espacios y experiencias diferentes al contexto del que proviene. Partimos de reconocer que en nuestra diversidad no sólo compartimos el desencanto, la indignación y la preocupación por el futuro, sino que también los esfuerzos por construir alternativas. En lugares distintos se gestan propuestas y procesos que nos unen y nos acercan al horizonte del buen vivir, a manera de un tejido compuesto por múltiples hebras que forman, entre todas, un nuevo e inacabado diseño.

En el recorrido por experiencias locales en busca de alternativas al desarrollo, podemos constatar la presencia del buen vivir -a veces explícita y a veces tácita, pero en ambos casos vigorosa- como un discurso que da sentido y orienta 
el quehacer de muchos actores. La noción penetra diferentes territorios, escalas y campos de acción y nuestro testimonio da fe de este rompimiento de fronteras. Está presente en zonas rurales, urbanas y periurbanas. Convoca a colectivos informales, grupos consolidados y redes ciudadanas. Se infiltra en las políticas públicas de los gobiernos de izquierda, se emplea para recuperar una infinidad de aspectos de nuestra vida colectiva, como el cuidado de espacios y bienes comunes, la convivencia y la producción sustentable. El buen vivir permite aflorar el compromiso para construir colectivamente entornos de vida más amables, justos y sustentables. Por su carácter abierto, el buen vivir se convierte en un marco amplio que actúa a manera de "zona de contacto" en el ejercicio de traducción entre la diversidad inagotable del mundo (Santos, 2009: 135-151) y nos facilita encontrar lo común en la diferencia. Descubrir estas convergencias nos estimula a promover intercambios, hilar alianzas y trabajar conjuntamente para mejorar estrategias y ampliar el impacto de nuestras acciones.

En esta región del mundo donde la devastación ambiental, la desigualdad y la violencia son generalizados y profundizados por la lógica y práctica del desarrollo, el buen vivir no es una panacea, pues solo es un horizonte que nos da esperanza, al mismo tiempo que nos demanda el trabajo personal y colectivo para el cambio. El carácter polisémico y abierto de la propuesta de buen vivir no debe verse como una desventaja sino un reto que se aborda en el hacer. En la acción acompañada por la reflexión, el buen vivir se dota de nuevo significado. Parafraseando a Eduardo Galeano, el buen vivir es la utopía que necesitamos para seguir caminando.

\section{AgRAdECIMIENTOS}

La autora desea agradecer a sus colaboradoras del Centro de Ecoalfabetización y Diálogo de Saberes y a los estudiantes de la Maestría en Estudios Transdisciplinarios para la Sostenibilidad; a las compañeras y los compañeros de la Red de Custodios del Área Natural Protegida, Espora Producciones y de la Caja Mágica; a los maestros, alumnas y alumnos de las escuelas de Xoloxtla, Rancho Viejo y Zoncuantla, y a los vecinos y las vecinas quienes nos acompañan con entusiasmo y compromiso en esta travesía hacia el buen vivir. 


\section{BIBLIOGRAFÍA}

Ayuntamiento de Xalapa (2019). Plan Municipal de Desarrollo 2018-2021 (actualización octubre 2019). Xalapa, México: Ayuntamiento de Xalapa.

Beauregard-García, M. L. (1986). Zona arqueológica de Xoloxtla, mpio. de Xalapa, Veracruz. Boletín Informativo del Instituto de Antropología, (5), pp. 9-14.

Bartra, A. (2010). De siembras barrocas y pensamientos salvajes: vivir bien es hacer milpa. La Jornada del Campo, (34), pp. 1-9.

Boff, L. (2002). El cuidado esencial. Ética de lo humano, compasión por la Tierra. Madrid, España: Editorial Trotta.

Boff, L. (2011). Ecología: grito de la tierra, grito de los pobres. Madrid, España: Editorial Trotta.

Bohm, D. (1997). Sobre el diálogo. Barcelona, España: Kairós.

Boege, E. (2008). El patrimonio biocultural de los pueblos indígenas de México. Hacia la conservación in situ de la biodiversidad y agrodiversidad en los territorios indígenas. Ciudad de México, México: INAH-CDI:SẸ]

Contreras-Hernández, A. (2010). Los cafetales de Veracruz y su contribución a la sistentabilidad. Estudios Agrarios, (45), pp. 143-161.

Encina, J., Ezeiza, A. (s/f). Conversatorio: participación y diálogo de saberes en los espacios y tiempos cotidianos. Texto de trabajo. Ilusionismo Social.

Encina, J., Rosa, M. (s/f). El uso de espacios y tiempos cotidianos como constructor de democracias ambientales en el Sur. Texto de trabajo. Ilusionismo Social.

Escobar, A. (1996). La invención del Tercer Mundo. Construcción y deconstrucción del desarrollo. Bogotá, Colombia: Norma.

Escobar, A. (2016). Sentipensar con la Tierra: Las luchas territoriales y la dimensión ontológica de las Epistemologías del Sur. Revista de Antropología Iberoamericana, 11(1), pp. 12-32. https://doi.org/10.11156/aibr.110102

Esteva, G., Babones, S., Babcicky, P. (2013). The future of development. A radical manifesto. Bristol, Reino Unido: Bristol Univerity Press. https://doi.org/10.2307/j.ctt1sq5vsw

Fondo Ambiental Veracruzano, Instituto de Ecología A. C., Secretaría de Medio Ambiente. (2018). Programa de Manejo del Área Natural Protegida Archipiélago de Bosques y Selvas de la Región Capital del Estado de Veracruz de Manejo. Xalapa, México: Gobierno del Estado de Veracruz.

Francisco-Hidalgo, F. (2011). Buen vivir, Sumak Kawsay: Aporte contrahegemónico del proceso andino. Utopía y Praxis Latinoamericana, 16(53), pp. 85-94.

Gudynas, E. (2011). Tensiones, contradicciones y oportunidades de la dimensión ambiental del Buen Vivir. En I. Farah, L. Vasapollo (eds.), Vivir bien: ¿Paradigma no capitalista? (pp. 231-246). La Paz, Bolivia: CIDES-UMSA, Plural.

Gudynas, E., Acosta, A. (2011). La renovación de la crítica al desarrollo y el buen vivir como alternativa. Utopía y Praxis Latinoamericana, 16(53), pp. 71-83.

Guigui, J.S., Paradowska, K., Cristiani, A. (2019). Xolostla. Voces y rostros [video documental]. Recuperado de https://www.youtube.com/watch?v=E1K1UbfkFNE 
Hensler, L., Merçon, J., González, R., Estrada, I., Paradowska, K., Bravo, L., Cesareo, V. (2019). Metodologías participativas para la cogestión del territorio. Una experiencia de aprendizaje colectivo en Veracruz, México. En P. Paño Yáñez, R. Rébola, M. Suárez Elías (eds.), Procesos y metodologías participativas. Reflexiones y experiencias para la transformación social (pp. 235-260). Ciudad de México, México: CLACSO-UDELAR. https://doi.org/10.2307/j.ctvtxw3sz.16

Hernández, L. (2010). Antes de empezar con metodologías participativas. Cuadernos CIMAS, pp. 1-31. Recuperado de http://www.redcimas.org/wordpress/wp-content/uploads/2012/08/m_DHernandez_ANTES.pdf

Huanacuni Mamani, F. (2010). Vivir Bien / Buen Vivir. Filosofía, politicas, estrategias y experiencias regionales andinas. Lima, Perú: Coordinadora Andina de Organizaciones Indígenas.

Illich, I. (2006-2008). Obras reunidas. Tomos I y II. Ciudad de México, México: Fondo de Cultura Económica.

Leff, E. (2004). Racionalidad ambiental. La reapropiación social de la naturaleza. Ciudad de México, México: Siglo XXI.

Leff, E. (2006). Aventuras de la epistemología ambiental: de la articulación de ciencias al diálogo de saberes. Ciudad de México, México: Siglo XXI.

Marañón, B. (ed.). (2014). Buen Vivir y descolonialidad. Crítica al desarrolllo y la racionalidad instrumentales. Ciudad de México, México: UNAM.

Merçon, J. (2017). Buen Vivir: Una casa en construcción. En: K. Paradowska (ed.), Tejiendo Utopías (pp. 9-14). Xalapa, México: Universidad Veracruzana.

Moguel, P., Toledo, V. M. (1996). El café en México, ecología, cultura indígena y sustentabilidad. Ciencias UNAM, (43), pp. 40-51.

Morin, E. (2004). La Epistemología de la Complejidad. Gazeta de Antropología, (20), pp. 43-77.

Morin, E., Ciurana, E. R., Motta, R. D. (2002). Educar en la era planetaria. Barcelona, España: Gedisa.

Nicolescu, B. (1996). La Transdisciplinariedad. Manifiesto. Colección "Transdisciplinariedad". París, Francia: Du Rocher.

Paradowska, K. (ed.). (2017). Tejiendo Utopías. Xalapa, México: Universidad Veracruzana.

Paradowska, K. (ed.). (2018). Talleres de Arte y Bien Vivir en Rancho Viejo. Xalapa, México: Códice-Centro de Ecoalfabetización, Diálogo de Saberes, Universidad Veracruzana.

Paradowska, K., Fabre, D. (2017). Tlan latamat. Contribuciones del concepto totonaco a la reconstrucción del Buen Vivir como invitación al diálogo. En K. Paradowska (ed.), Tejiendo Utopías (pp. 23-32). Xalapa, México: Universidad Veracruzana.

Paré, L., Gerez, P. (eds.). (2012). Al filo del agua: cogestión de la subcuenca del río Pixquiac. Veracruz, México: Secretaría de Medio Ambiente y Recursos Naturales-Instituto Nacional de Ecología.s[epi]

Robledo, A., Carmona, A., Palma, R. (2016). Una visión del Archipiélago desde la perspectiva del crecimiento urbano. El Jarocho Cuántico al son de la ciencia. Suplemento Científico de La Jornada Veracruz, (64). Recuperado de http://www.jornadaveracruz.com.mx/extras/20167/160702_202.pdf 
Rodríguez, R., Paradowska, K., Bravo, L. (2019). El monte me jala. Las historias de Don Moi en el bosque de niebla [Cortometraje animado]. Recuperado de https://www.youtube.com/watch?v=oaAm8evU9PY

Rodríguez-Villasante, T. (2014). Redes de vida desbordantes. Fundamentos para el cambio desde la vida cotidiana. Madrid, España: Catarata.

Sachs, W. (1997). Arqueología de la Idea de Desarrollo. Revista Envío, (185), pp. 98-124.

Santos, de Sousa B. (2009). Una epistemología del Sur: la reinvención del conocimiento y la emancipación social. Ciudad de México, México: Siglo XXI Editores-CLACSO.

Sartorello, S., Ávila, L., Ávila, A. (eds.). (2012). El Buen Vivir: miradas desde adentro de Chiapas. Ciudad de México, México: UNICH-IESALS-UNESCO.

Universidad Veracruzana. (2008). Plan de Estudios de la Maestría en Estudios Transdisciplinarios para la Sostenibilidad. Xalapa: Centro de Ecoalfabétización y Diálogo de Saberes, Universidad Veracruzana.

Valderrama-Rouy, P. (2017). La cultura campesina de la milpa y el buen vivir. En K. Paradowska (ed.), Tejiendo Utopías (pp. 95-110). Xalapa, México: Universidad Veracruzana.

Williams-Linera, G. (2007). El bosque de niebla del centro de Veracruz: ecología, historia y destino en tiempos de fragmentación y cambio climático. Xalapa, México: CONABIO - Instituto de Ecología, A.C. 